\title{
Effect of UV/chlorine treatment on photophysical and photochemical properties of dissolved organic matter
}

\author{
Yangjian Zhou a,b,1, Fangyuan Cheng ${ }^{\mathrm{a}, 1}$, Dongyang He ${ }^{\mathrm{a}}$, Ya-nan Zhang ${ }^{\mathrm{a}, *}$, Jiao Qu ${ }^{\mathrm{a}, *}$, \\ Xin Yang ${ }^{\mathrm{b}}$, Jingwen Chen ${ }^{\mathrm{c}}$, Willie J.G.M. Peijnenburg d,e \\ a State Environmental Protection Key Laboratory of Wetland Ecology and Vegetation Restoration, School of Environment, Northeast Normal University, \\ Changchun 130117, China \\ ${ }^{\mathrm{b}}$ School of Environmental Science and Engineering, Guangdong Provincial Key Laboratory of Environmental Pollution Control and Remediation Technology, \\ Sun Yat-sen University, Guangzhou 510275, China \\ ${ }^{\mathrm{c}}$ Key Laboratory of Industrial Ecology and Environmental Engineering (MOE), School of Environmental Science and Technology, Dalian University of \\ Technology, Dalian 116024, China \\ d Institute of Environmental Sciences, Leiden University, Leiden, the Netherlands \\ e National Institute of Public Health and the Environment (RIVM), Center for Safety of Substances and Products, Bilthoven, the Netherlands
}

\section{A R T I C L E I N F O}

\section{Article history:}

Received 8 September 2020

Revised 15 January 2021

Accepted 17 January 2021

Available online 20 January 2021

\section{Keywords:}

Dissolved organic matter

UV/chlorine

Photophysical properties

Photochemical properties

Photodegradation

\begin{abstract}
A B S T R A C T
Dissolved organic matter (DOM) is a ubiquitous component in effluents, DOM discharged with an effluent can affect the composition and properties of natural DOM in the receiving waters. As the photophysical and photochemical properties of effluent DOM can be changed by wastewater treatment processes, the effect of UV/chlorine treatment on the photophysical and photochemical properties of DOM was investigated using Suwannee River fulvic acid (SRFA) and Suwannee River natural organic matter (SRNOM) as representatives. Results showed that the absorbance of the two DOM was significantly decreased. The evolution trends of three representative photophysical parameters upon increase of chlorine dosages were observed. Also, a decrease in DOM aromaticity, molecular weight and electron-donating capacity was observed upon increasing chlorine dosage. Quantum yields of excited triplet state of DOM $\left({ }^{3} \mathrm{DOM}^{*}\right)$, singlet oxygen $\left({ }^{1} \mathrm{O}_{2}\right)$ and hydroxyl radicals $(\cdot \mathrm{OH})$ first decreases and then increased in the UV/chlorine systems upon increasing chlorine dosages due to the different reaction pathways of the two DOM. Moreover, ${ }^{3} \mathrm{DOM}^{*}$ can not only be regarded as a "controller" of other reactive intermediates, but also effectively promote the photodegradation of bezafibrate, which is classified as a persistent organic contaminant. This study gives deep insights into effects of UV/chlorine on the photophysical and photochemical properties of DOM, and is helpful for understanding the dynamic roles of DOM in the photodegradation of micropollutants.
\end{abstract}

(C) 2021 Elsevier Ltd. All rights reserved.

\section{Introduction}

Dissolved organic matter (DOM), which is among the most complex molecular mixtures of biotically and abiotically degraded biomolecules known, plays amongst others an important role in the photochemical processes in the aquatic environment (Zark and Dittmar, 2018; Zhang et al., 2018a). The photophysical and photochemical properties of DOM isolated from natural waters and their roles in the photodegradation of emerging pollutions are of great interest and have been investigated in many previously

\footnotetext{
* Corresponding authors.

E-mail addresses: zhangyn912@nenu.edu.cn (Y.-n. Zhang), quj100@nenu.edu.cn (J. Qu).

1 Yangjian Zhou and Fangyuan Cheng contributed equally to this work.
}

(Leresche et al., 2019; Mostafa and Rosario-Ortiz, 2013; Wang et al., 2018). In recent years, effluent organic matter (EfOM) isolated from the effluent of wastewater treatment plants (WWTPs), which refers to NOM that has been modified during wastewater treatment, also received much attention as EfOM can alter the photoreactivity of natural DOM in the receiving waters (Zhang et al., 2014).

The photophysical properties of DOM are mainly assessed using the absorption ability of light (McKay et al., 2018), including specific ultraviolet absorbance (e.g., at $254 \mathrm{~nm}, S U V A_{254}$ ), the ratio of DOM absorbance at 254 to $365 \mathrm{~nm}\left(E_{2} / E_{3}\right.$ ratio), and slope characteristics $\left(S, \mathrm{~nm}^{-1}\right)$ of the absorbance spectrum (Twardowski et al., 2004; Weishaar et al., 2003). It was reported that the optical properties of EfOM differ when compared with natural DOM (Bodhipaksha et al., 2015), and of seawater DOM when compared with freshwater DOM (Wang et al., 2019) due to the differences in 
chemical composition were reported. Thus, the DOM with different sources or undergo any chemical treatment that may induce the degradation of DOM are with different photophysical properties (Laszakovits et al., 2020; Wang et al., 2019).

Upon irradiation, the ground state DOM reaches its excited singlet state $\left({ }^{1} \mathrm{DOM}^{*}\right)$, and then undergoes intersystem crossings (ISC) via spin orbital couplings to the triplet excited state $\left({ }^{3} \mathrm{DOM}^{*}\right)$ (McNeill and Canonica, 2016). Both ${ }^{1} \mathrm{DOM}^{*}$ and ${ }^{3} \mathrm{DOM}^{*}$ can fall back to the ground state of DOM via fluorescence/phosphorescence emission and nonradiative transition, which are the photophysical processes of DOM (McNeill and Canonica, 2016). Besides, ${ }^{3} \mathrm{DOM}^{*}$ can take part in the redox reaction of organic pollutants via energy transfer or electron transfer, and is an important precursor of reactive oxygen species (ROS) such as singlet oxygen $\left({ }^{1} \mathrm{O}_{2}\right)$ and the hydroxyl radical $(\cdot \mathrm{OH})$ (Dalrymple et al., 2010; Dong and RosarioOrtiz, 2012). These reactive species can initiate the indirect photolysis of various emerging pollutants in natural water (Apell et al., 2019; Ge et al., 2019; Zhou et al., 2019c). Furthermore, DOM can also inhibit the photodegradation of micropollutants via either light screening or quenching effect (Janssen et al., 2014).

DOM from different sources has been proven to possess different photochemical properties (Lee et al., 2013; Wang et al., 2020). The ${ }^{3} \mathrm{DOM}^{*},{ }^{1} \mathrm{O}_{2}$, and $\cdot \mathrm{OH}$ formation quantum yields of EfOM are higher compared with natural DOM (Bodhipaksha et al., 2015; Zhang et al., 2014), and the ${ }^{3} \mathrm{DOM}^{*}$ formation quantum yields of seawater DOM are higher compared with freshwater DOM (Wang et al., 2019). This leads to different effects of DOM isolated from different waters on the photodegradation of micropollutants (Wang et al., 2019). Although many studies have investigated the properties of different DOM and their effects on the photodegradation of micropollutants, little is known about the effects of sewage treatment technologies on the properties of DOM of the effluents.

UV irradiation, and sometimes UV/chlorine, is frequently used for the disinfection in WWTPs, and UV/chlorine based advanced oxidation processes (AOPs) were recently developed for the removal of recalcitrant micropollutants in wastewater (Fang et al., 2014). Various highly reactive electrophilic radicals, such as $\cdot \mathrm{OH}$ and reactive chlorine species (RCS) are produced during the UV/chlorine treatment (Guo et al., 2017; Zhou et al., 2019b), and they play important roles in the degradation of micropollutants and in the inactivation of water-borne pathogens (Duan et al., 2018; Xiang et al., 2016).

UV/chlorine treatment was proven to degrade humin acid (Gao et al., 2019), and induced reactions in the aliphatic, olefinic and aromatic components of DOM (Varanasi et al., 2018; Zhang and Parker, 2018). Among which, the reaction rate constant of chlorine radial $\left(\mathrm{Cl}^{\cdot}\right)$ with aromatic structures reaches up to $10^{10} \mathrm{M}^{-1} \mathrm{~s}^{-1}$ level via single electron transfer or chlorine addition (Varanasi et al., 2018). Furthermore, it has been demonstrated that ozone treatment can change the molecular structure of DOM, thereby significantly affecting the photophysical and photochemical properties of DOM (Leresche et al., 2019). For instance, an increase in the quantum yields of ${ }^{1} \mathrm{O}_{2}$ and fluorescence after ozone treatment were observed (Leresche et al., 2019). Thus, it can be hypothesized that the synergistic effect of UV irradiation and reactive species induced changes in the composition of DOM can lead to a significant variation of its properties. However, the influence of $\mathrm{UV} /$ chlorine treatment on the properties of DOM is still unclear.

In this study, the effect of UV/chlorine treatment, a common step in sewage treatment, on the photophysical and photochemical properties of DOM was investigated. Suwanee River fulvic acid (SRFA) and Suwanee River natural organic matter (SRNOM) were selected as DOM isolates. The optical properties and the apparent quantum yields of ${ }^{3} \mathrm{DOM}^{*},{ }^{1} \mathrm{O}_{2}$, and $\cdot \mathrm{OH}$ of the two types of DOM were determined during the UV/chlorine treatment. Besides, to investigate the effect of treated DOM on the photodegradation of micropollutants, bezafibrate (BZF) was selected as a target contaminant, which is a widely used lipid regulator and is frequently detected in wastewater, in sewage effluents and in natural water (Zhou et al., 2019c). The contribution of different reactive species generated from DOM treated by the UV/chlorine was evaluated.

\section{Materials and methods}

\subsection{Chemicals}

BZF (98\%), sorbic acid (SA, 99\%), sodium azide $\left(\mathrm{NaN}_{3}, 98 \%\right)$, 2,4,6-trimethylphenol (TMP, 98\%), furfuryl alcohol (FFA, 98\%), isopropanol (IPA, 99\%), benzene (99\%), phenol ( $\mathrm{PhOH}, 99 \%)$, nitrobenzene (NB, 98\%), benzoic acid (BA, 98\%), benzophenone (BP, 98\%), hydroquinone (HQ 98\%), 4-hydroxybenzophenone (4hBP, 98\%), 4-chloro-4'-hydroxybenzophenone (4-Cl-4hBP, 98\%), 2chlorohydroquinone (2-Cl-HQ 95\%), p-benzoquinone ( $p$-BQ, 99\%), sodium perchlorate $\left(\mathrm{NaClO}_{4}\right)$ and sodium hypochlorite solution (available chlorine 5\%) were purchased from JEK Scientific Ltd. (Beijing, China); sodium dihydrogen phosphate $\left(\mathrm{NaH}_{2} \mathrm{PO}_{4}\right)$ and disodium hydrogen phosphate $\left(\mathrm{Na}_{2} \mathrm{HPO}_{4}\right)$ purchased from Tianjin Damao Chemical (Tianjin, China). Organic solvents used in this study with chromatographical purity were obtained from TEDIA (Fairfield, OH, USA). Suwannee River fulvic acid Standard II (SRFA, 2S101F) and Suwannee River NOM (SRNOM, 2R101N) were purchased from the International Humic Substances Society. Ultrapure water (18.2 $\mathrm{M} \Omega$ ) was obtained from a purification system produced by Chengdu Ultrapure Technology Co., Ltd. (Chengdu, China).

\subsection{UV/chlorine treatment experiments}

UV/chlorine photochemical experiments were conducted at least in triplicate inside an OCRS-PX32T merry-go-round photoreactor (Kaifeng Hxsei Science Instrument Factory, China) equipped with a motorized turntable. A $500 \mathrm{~W} \mathrm{Hg}$ lamp (254 nm) was used as the UV light source, and the light intensity at $\lambda=254 \mathrm{~nm}$ was measured to be $(1.45 \pm 0.07) \mathrm{mW} \mathrm{cm}^{-2}$ using a UV-B dualchannel ultraviolet radiation meter (Photoelectric Instrument Factory of Beijing Normal University, China). During the photochemical experiment, a condensation device was used, and the reactor was kept ventilated to control the temperature of the solutions steady during UV irradiation.

SRNOM and SRFA were added at an initial concentration of $10 \mathrm{mg} \mathrm{L}^{-1}$, and different dosages of chlorine $(0,25,50,75,100$, 125, 150, $200 \mu \mathrm{M}$ ) were added. Phosphate buffer solution (PBS) was used to control the solution $\mathrm{pH}$ at 7.0. UV irradiation experiments were performed in the photochemical reactor for $10 \mathrm{~min}$, and some quartz tubes were covered with aluminum foil as dark controls. $\mathrm{NaClO}_{4}$ was used to control the ionic strength in some experiments. After UV/chlorine treatment, the photolysis solution was stored in the dark at room temperature. The residual chlorine was detected using the $\mathrm{N}, \mathrm{N}$-diethyl-1,4-phenylenediamine sulfate (DPD) method (China, HJ 586-2010 2010). DPD can react with free chlorine and generate colored compounds which show significant UV absorbance at $515 \mathrm{~nm}$. The solutions were used in the subsequent experiments until its residual chlorine was less than $0.05 \mathrm{mg}$ $\mathrm{L}^{-1}$.

Under UV/chlorine treatment, $\mathrm{NB}$ and $\mathrm{BA}$ were used as the probe chemicals to measure the steady-state concentrations of $\cdot \mathrm{OH}$ and $\mathrm{Cl} \cdot\left([\cdot \mathrm{OH}]_{S S}\right.$ and $\left.[\mathrm{Cl} \cdot]_{S S}\right)$, respectively (Varanasi et al., 2018), as detailed in the Text S1 in the supplementary information (SI). However, kinetic models are used to calculated the steady-state concentrations of $\mathrm{ClO}$. and $\mathrm{Cl}_{2} \cdot-\left([\mathrm{ClO} \cdot]_{\mathrm{SS}}\right.$ and $\left.\left[\mathrm{Cl}_{2} \cdot{ }^{-}\right]_{\mathrm{SS}}\right)$ (Table $\left.\mathrm{S} 1\right)$. This was needed because of lack of the probe compounds. Version 6.80 of the Kintecus software is a compiler to model and 
regress/fit/optimize the reactions (Ianni, 2019). This software requires only the formula for the reaction kinetics and a reaction rate constant to fit the steady-state concentration of reactive radicals in the system (Table S1).

\subsection{Spectroscopic measurements}

During UV/chlorine treatment, samples containing SRFA or SRNOM were withdrawn and the absorption spectra of SRFA and SRNOM were determined using a Ultraviolet-visible Spectrophotometer (Hitachi-U2900, Japan). Based on the results of the UVvisible absorption spectrum, the photophysical properties, including $E_{2} / E_{3}$, spectral slope $(S)$, special UV absorption $\left(\mathrm{SUVA}_{254}\right)$, and wavelength-average specific absorption coefficient (SUVA $\mathrm{avg}_{\mathrm{ag}}$ ) of the two DOM were calculated; the detailed definition and calculation methods are described in Text S2.

\subsection{Determination of photochemical properties of SRFA and SRNOM during UV/chlorine treatment}

The photochemical properties of SRFA, SRNOM, SRFA after $\mathrm{UV} /$ chlorine treatment (SRFA-UV/Cl) and SRNOM after UV/chlorine treatment (SRNOM- UV/Cl) were determined in an XPA-7 merrygo-round photoreactor (Xujiang Electromechanical Plant, Nanjing, China) with $500 \mathrm{~W} \mathrm{Hg}$ lamp equipped with $290 \mathrm{~nm}$ filters as the simulated sunlight. The light intensity at the surface of the quartz tubes was detected with a TriOS-RAMSES spectroradiometer (TriOS $\mathrm{GmbH}$, Germany), and the result is shown in Fig. S1. TMP, FFA and benzene were used as the probe chemicals to measure the apparent quantum yields and steady-state concentrations of excited triplet DOM $\left({ }^{3} \mathrm{DOM}^{*}\right),{ }^{1} \mathrm{O}_{2}$ and $\cdot \mathrm{OH}$, respectively (Zhou et al., 2018). Apparent quantum yields of reactive intermediates $\left(\Phi_{\mathrm{RIs}}\right)$ were calculated by the following equation (Zhao et al., 2020; Zhou et al., 2018):

$\Phi_{\mathrm{RIs}}=\frac{R_{\mathrm{RIs}}}{\sum_{\lambda} k_{\mathrm{X}-\mathrm{a}}(\lambda)[\mathrm{X}]}$

$k_{\mathrm{X}-\mathrm{a}}(\lambda)=\frac{I_{p} \varepsilon_{X}(\lambda)\left(1-10^{-\left(\alpha(\lambda)+\varepsilon_{\mathrm{X}}(\lambda)[\mathrm{X}]\right) z}\right)}{\left(\alpha(\lambda)+\varepsilon_{\mathrm{X}}(\lambda)[\mathrm{X}]\right) z}$

where $R_{\mathrm{RIs}}$ is the formation rates of specific RIs $\left(\mathrm{M} \mathrm{s}^{-1}\right)$, and as can be calculated from (Text S3), [X] is concentration of a specific photosensitizer $(\mathrm{M}) . k_{\mathrm{a}}(\lambda)$ is the specific rate of light absorption $\left(\mathrm{s}^{-1}\right)$, and can be calculated from Eq. (2). The $\Phi_{\mathrm{RIs}}$ values were calculated from 290 to $400 \mathrm{~nm}$ due to the relative insignificance of wavelengths $>400 \mathrm{~nm}$. $I_{\mathrm{p}}$ is the incident intensity (Einstein $\mathrm{s}^{-1}$ $\left.\mathrm{cm}^{-2}\right), \varepsilon_{\mathrm{X}}(\lambda)$ is the molar absorption coefficient of the photosensitizer $\left(\mathrm{M}^{-1} \mathrm{~cm}^{-1}\right), z$ is the optical path $(\mathrm{cm}), \alpha(\lambda)$ is the unit absorbance of the background matrix $\left(\mathrm{cm}^{-1}\right)$.

The details of the calculation methods of the steady-state concentrations of ${ }^{3} \mathrm{DOM}^{*}\left(\left[{ }^{3} \mathrm{DOM}^{*}\right]_{\mathrm{SS}}\right),{ }^{1} \mathrm{O}_{2}\left(\left[{ }^{1} \mathrm{O}_{2}\right]_{\mathrm{SS}}\right)$ and $\cdot \mathrm{OH}\left([\cdot \mathrm{OH}]_{\mathrm{SS}}\right)$ are shown in the Text S3.

\subsection{Photodegradation of BZF}

Considering the change of DOM concentration under UV/chlorine treatment, we used the same total organic carbon (TOC) concentration of DOM as a control to study the change of photoreactivity and its effect on the photodegradation of BZF. In order to investigate the effect of excited triplet, ${ }^{1} \mathrm{O}_{2}$, and $\cdot \mathrm{OH}$, quenching experiments were carried out with $\mathrm{SA}(2 \mathrm{mM})$ as excited triplet quencher, $\mathrm{NaN}_{3}(2 \mathrm{mM})$ as ${ }^{1} \mathrm{O}_{2}$ and $\cdot \mathrm{OH}$ quencher, and IPA (20 $\mathrm{mM}$ ) as $\cdot \mathrm{OH}$ quencher (Zhou et al., 2018).

\subsection{Analytical methods}

A Shimadzu LC-20A HPLC system (Shimadzu, Kyoto, Japan) with a UV-Vis detector and an Ultimate ${ }^{\mathrm{TM}}$ AQ-C18 column (250 mm $\times 4.6 \mathrm{~mm}, 5 \mathrm{~mm}$, Welch Materials, Maryland, USA) was employed for the quantification of NB, BA, FFA, TMP, PhOH and BZF, as detailed in the Table S2. Dissolved organic carbon (DOC) concentrations of SRFA and SRNOM before and after UV/chlorine were measured with a Shimadzu TOC-5000 analyzer using hightemperature combustion.

\section{Results and discussion}

\subsection{Photophysical properties of SRFA and SRNOM before and after UV/chlorine treatment}

UV-vis spectra of SRFA and SRNOM before and after $\mathrm{UV} /$ chlorine treatment with different chlorine dosages $(0-200 \mu \mathrm{M})$ were determined, and the results are shown in Fig. 1. The absorbance intensity of SRFA and SRNOM decreased after UV irradiation (Fig. $1 \mathrm{~A}$ and $\mathrm{C}, \mathrm{Cl}-0$ vs. initial), indicating that UV-induced degradation can weakens the light absorption ability of the two DOM. The addition of chlorine further weakened the absorption ability and the absorbance intensity of SRFA and SRNOM decreased with increasing chlorine dosage (Fig. $1 \mathrm{~A}$ and $\mathrm{C}$ ), This can lead to a decreased light screening effect on the photodegradation of micropollutants. The absorbance of SRFA and SRNOM showed no obvious difference during $\mathrm{UV} /$ chlorine treatment in the dark control (Fig. S2), implying that UV irradiation is essential for the degradation of SRFA and SRNOM. The effect of ionic strength, as determined by adding $\mathrm{NaClO}_{4}$ under UV irradiation, was found not to significantly change the absorbance of the two types of DOM. This effect is opposite to the observations in the presence sodium hypochlorite (Fig. S2), which indicates that the decrease of light absorption of the two DOM is ionic strength-independent.

As the changes of the absorbance were quite small, the linear differential absorbance (DA) spectra were used, as commonly done in previous studies (Korshin et al., 2007; Yan et al., 2014). The intensity of DA was calculated (detailed method is shown in Text S4) and the results showed that the DA for SRFA and SRNOM significantly increased with the increase of chlorine dosage (Fig. 1B and D). Previous studies reported that reactive radicals (e.g., $\mathrm{Cl}$. and . OH) generated during $\mathrm{UV} /$ chlorine treatment have a high reaction rate constant with DOM ( 10 $\left.\mathrm{L} \mathrm{mg}^{-1} \mathrm{~s}^{-1}\right)$ (Guo et al., 2017), and induce the degradation of DOM (Varanasi et al., 2018). This could lead to the changes of its light absorption ability. Thus, the steady-state concentrations of reactive radicals (RCS and . $\mathrm{OH}$ ) in the UV/chlorine treatment system with different chlorine dosages were calculated by the kinetic model according to the methods described in Text S1 and Table S1 (Guo et al., 2017). The steady-state concentrations of RCS and $\cdot \mathrm{OH}$ increased with the increase of chlorine dosage during the UV/chlorine treatment (Fig. S3). This is the reason for the observed decrease of light absorbance of the two DOM. The influence of UV/chlorine treatment on the absorbance of SRFA is stronger compared to SRNOM (Fig. 1B and D). This is supposed to be attributed to the different reactivity of SRNOM and SRFA with these reactive species.

Three representative parameters $\left(E_{2} / E_{3}, S_{U V A} A_{24}\right.$ and $\left.S\right)$ were calculated to further investigate the effect of UV/chlorine treatment on the photophysical properties of SRFA and SRNOM (Text S2). The results showed that $E_{2} / E_{3}$ and $S$ of SRFA and SRNOM increased with the increase of chlorine dosage, while $S_{U V A}{ }_{254}$ of the two DOM decreased with the increase of chlorine dosage under UV irradiation (Fig. 2). These results indicated that the aromaticity and the molecular weight of DOM were reduced. Aromatic structures or other functional groups that have high reactivity with RCS 

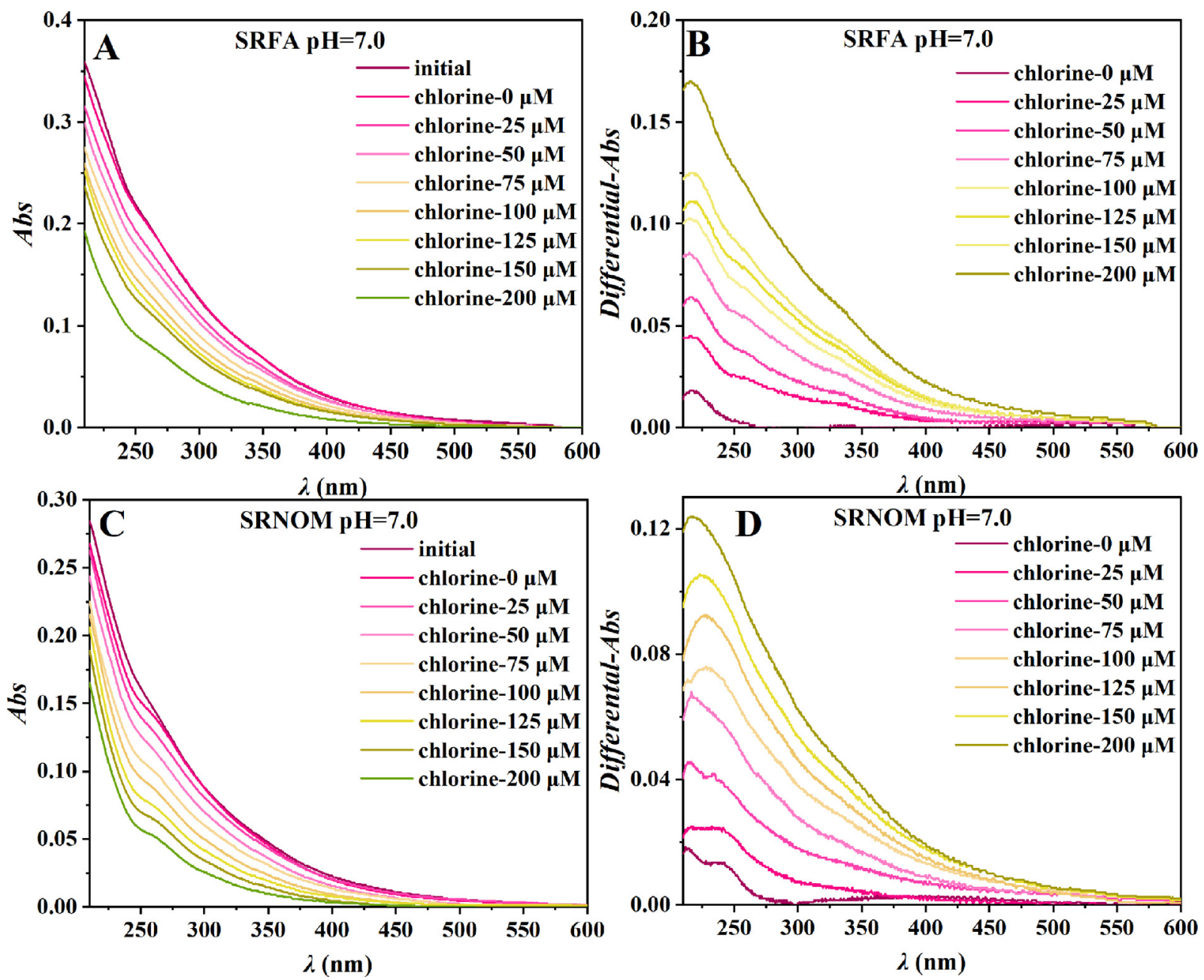

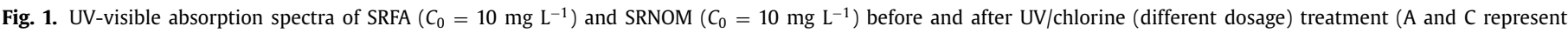

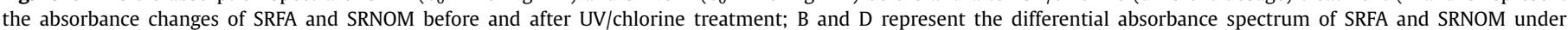
$\mathrm{UV} /$ chlorine treatment).
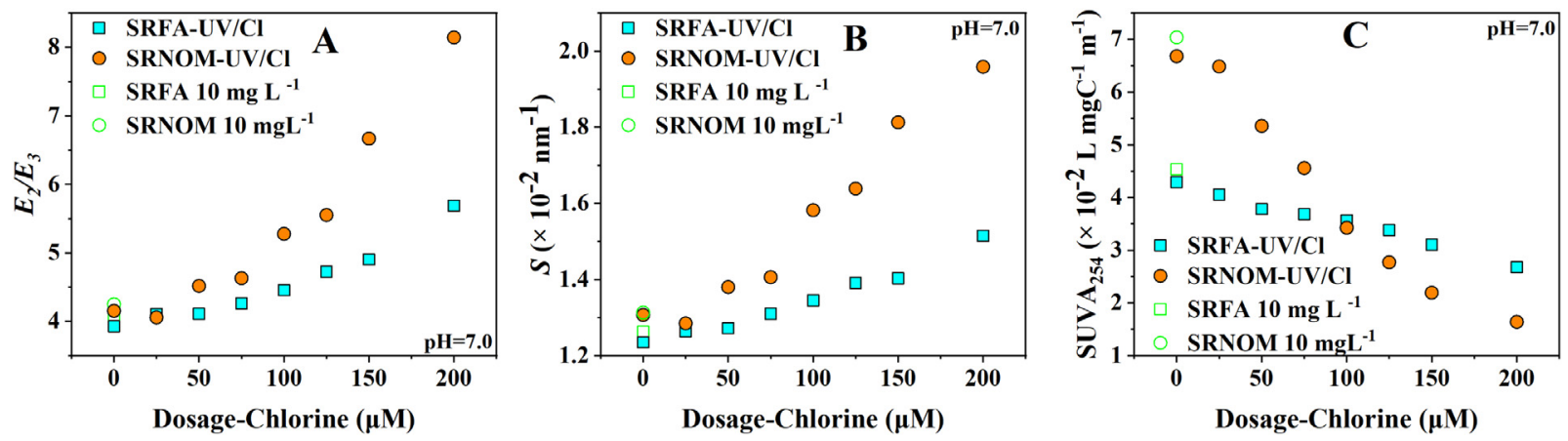

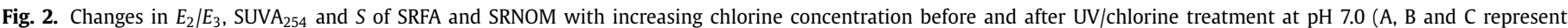

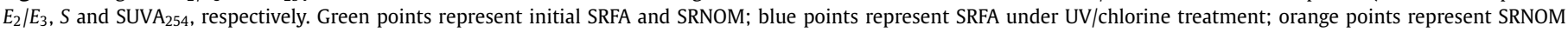
under UV/chlorine treatment). (For interpretation of the references to colour in this figure legend, the reader is referred to the web version of this article.)

or $\cdot \mathrm{OH}$ (e.g., olefinic structure) are easily oxidized by these reactive species, leading to functional group cleavage, and eventual conversion into low molecular-weight ring-opened compounds or mineralized products (Fang et al., 2014; Zhang and Parker, 2018). The aromaticity and molecular weight of SRFA and SRNOM were calculated based on the method described in Text S2. The aromaticity of SRFA and SRNOM were found to decrease from 3.93\% to $3.80 \%$ and $4.09 \%$ to $3.74 \%$, respectively as the chlorine dosage increased from 0 to $200 \mu \mathrm{M}$ (Table S3), whereas the molecular weight of
SRFA and SRNOM decreased from 2.63 to $1.10 \mathrm{kDa}$ and from 2.53 to $0.68 \mathrm{kDa}$, respectively (Table $\mathrm{S} 4$ ).

It has been reported that $E_{2} / E_{3}$ is correlated inversely with the electron-donating capacity of DOM (Helms et al., 2008; Sharpless et al., 2014). The shift in $E_{2} / E_{3}$ suggested that $\mathrm{UV} /$ chlorine treatment decreased the electron-donating capacity of SRFA and SRNOM. Moreover, the growth rates of $E_{2} / E_{3}$ and $S$ and the reduction rate of $\mathrm{SUVA}_{254}$ is faster for SRNOM than for SRFA (Fig. 2). This indicates that the changes of aromaticity and molec- 
Table 1

Photochemical properties of SRFA $\left(C_{0}=10 \mathrm{mg} \mathrm{L}^{-1}\right)$, SRNOM $\left(C_{0}=10 \mathrm{mg} \mathrm{L}^{-1}\right)$, and six DOM-analogs $\left(C_{0}=5 \mathrm{mg} \mathrm{L}^{-1}\right)$ at pH 7.0 .

\begin{tabular}{lllllll}
\hline Sample & $\Phi_{3 \mathrm{DOM}^{*}}\left(\times 10^{-3}\right)$ & {$\left[{ }^{3} \mathrm{DOM}^{*}\right]_{\mathrm{SS}}\left(\times 10^{-14}\right)$} & $\Phi_{1 \mathrm{O} 2}\left(\times 10^{-2}\right)$ & {$\left[{ }^{1} \mathrm{O}_{2}\right]_{\mathrm{SS}}\left(\times 10^{-13}\right)$} & $\Phi_{. \mathrm{OH}}\left(\times 10^{-5}\right)$ & {$[\cdot \mathrm{OH}]_{\mathrm{SS}}\left(\times 10^{-17}\right)$} \\
\hline SRFA & $4.66 \pm 0.10$ & $2.95 \pm 0.08$ & $1.99 \pm 0.02$ & $3.26 \pm 0.02$ & $5.61 \pm 0.11$ & $5.24 \pm 0.05$ \\
SRNOM & $4.07 \pm 0.16$ & $3.44 \pm 0.05$ & $1.88 \pm 0.17$ & $3.14 \pm 0.17$ & $4.19 \pm 0.14$ & $5.36 \pm 0.04$ \\
BP & $10.50 \pm 2.10$ & $69.69 \pm 1.38$ & $8.48 \pm 0.09$ & $11.83 \pm 1.41$ & $4.42 \pm 0.01$ & $4.14 \pm 0.06$ \\
4-hBP & $0.036 \pm 0.002$ & $3.54 \pm 0.25$ & $0.036 \pm 0.001$ & $0.70 \pm 0.03$ & $0.31 \pm 0.01$ & $4.04 \pm 0.01$ \\
4-Cl-4hBP & $0.033 \pm 0.002$ & $3.16 \pm 0.01$ & $0.016 \pm 0.002$ & $0.31 \pm 0.05$ & $0.30 \pm 0.02$ & $4.09 \pm 0.02$ \\
HQ & $0.174 \pm 0.01$ & $0.77 \pm 0.02$ & $1.006 \pm 0.003$ & $0.93 \pm 0.07$ & $3.17 \pm 0.12$ & $6.94 \pm 0.08$ \\
2-Cl-HQ & $0.145 \pm 0.015$ & $1.22 \pm 0.04$ & $0.879 \pm 0.004$ & $1.55 \pm 0.12$ & $0.68 \pm 0.04$ & $6.04 \pm 0.07$ \\
p-BQ & $0.221 \pm 0.025$ & $1.98 \pm 0.01$ & $2.92 \pm 0.01$ & $2.86 \pm 0.12$ & $9.56 \pm 0.32$ & $8.59 \pm 0.17$ \\
\hline
\end{tabular}

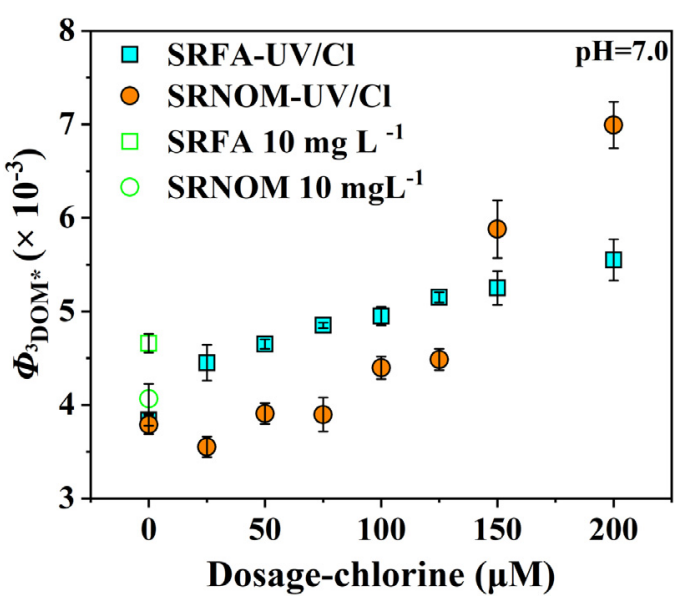

Fig. 3. Changes in $\Phi_{3 \mathrm{DOM}^{*}}$ of SRFA and SRNOM with increasing chlorine dosage before and after UV/chlorine treatment at $\mathrm{pH} 7.0$ (Green points represent initial SRFA and SRNOM; blue points represent SRFA under UV/chlorine treatment; orange points represent SRNOM under UV/chlorine treatment). (For interpretation of the references to colour in this figure legend, the reader is referred to the web version of this article.)

ular weight for SRNOM were more than those of SRFA during UV/chlorine treatment. This can also be confirmed by the calculated removal rates of aromaticity and molecular weight for the two DOM after UV/chlorine treatment (chlorine dosage is $200 \mu \mathrm{M}$ ) as the removal rates were respectively 2.59 and 1.26 times higher than for SRFA (Table S3; Table S4). The predominant reason for this phenomenon is that SRNOM has a stronger electron donating capacity compared with SRFA (Walpen et al., 2016), and the RCS have higher reactivity with substances possessing stronger electron donating capacity (Varanasi et al., 2018).

\subsection{Effect of UV/chlorine treatment on ${ }^{3} D O M^{*}$ generation from SRFA and SRNOM}

The quantum yields of ${ }^{3} \mathrm{DOM}^{*}\left(\Phi_{3 \mathrm{DOM}^{*}}\right)$ from SRFA and SRNOM were determined to be $(4.66 \pm 0.10) \times 10^{-3}$ and $(4.07 \pm 0.16) \times 10^{-3}$, respectively (Table 1$)$, which is in the same order of magnitude as reported in a previous study (Wang et al., $2019)$. After UV irradiation, the $\Phi_{3 \mathrm{DOM}^{*}}$ of SRFA and SRNOM decreased to be $(3.84 \pm 0.06) \times 10^{-3}$ and $(3.79 \pm 0.10) \times 10^{-3}$, respectively (Fig. 3). These results indicated that the photosensitizing chromophores of the two DOM were damaged during the UV irradiation treatment. The $\Phi_{3 \mathrm{DOM}^{*}}$ of SRFA-UV/Cl increased was observed upon increasing chlorine dosages. The $\Phi_{3 \mathrm{DOM}^{*}}$ of SRFA$\mathrm{UV} / \mathrm{Cl}$ was higher than the $\Phi_{3 \mathrm{DOM}^{*}}$ of SRFA at relatively high chlorine dosages of $75 \mu \mathrm{M}$ and more (Fig. 3). The different effect on the $\Phi_{3 \mathrm{DOM}^{*}}$ of SRFA in the absence and presence of chlorine is attributed to the different reaction pathways of the two reaction processes: (1) UV irradiation mainly induced the bond-cleavage reaction of DOM or a small amount of reactive oxygen species (e.g., ${ }^{1} \mathrm{O}_{2}$ and $\cdot \mathrm{OH}$ ) produced by DOM caused self-sensitized photolysis (Sharpless et al., 2014). (2) In the presence of chlorine, a large amount of RCS and $\cdot \mathrm{OH}$ were generated, which could react with DOM by an addition reaction (hydroxyl or chlorine addition), single electron transfer or bond breaking (Varanasi et al., 2018; Zhang et al., 2018b), resulting in the generation of more complex functional groups (e.g., aromatic ketones or quinones) (Duan et al., 2018).

At lower chlorine dosages $(25-50 \mu \mathrm{M})$, the values of $\Phi_{3 \mathrm{DOM}^{*}}$ of SRFA-UV/Cl are lower compared with those of SRFA, and higher than the $\Phi_{3 \mathrm{DOM}^{*}}$ of SRFA after UV irradiation (Fig. 3). This is attributed to low concentrations of RCS and $\cdot \mathrm{OH}$ in the presence of low chlorine dosages (Fig. S3). Thus, the UV-induced photodegradation accounts for a large proportion of the overall reactivity observed. Meanwhile, at low chlorine dosages, -OH or RCS predominantly induce addition reactions when oxidizing SRFA. $\mathrm{Cl}$. is highly reactive in inducing addition reactions with organic matters $\left(k \approx 10^{8}-10^{9} \mathrm{M}^{-1} \mathrm{~s}^{-1}\right)$ (Gilbert et al., 1988; Lei et al., 2019), whereas previous studies have shown that the oxidation of aromatic substances by -OH occurs firstly by means of hydroxyl addition, followed by electron transfer forming quinones, and finally cleavage of the benzene ring (Zhang et al., 2016). The addition reactions induced by low concentration $\cdot \mathrm{OH}$ or RCS in the reduction of $\Phi_{3 \mathrm{DOM}^{*}}$.

Five low molecular DOM analogs (BP, HQ 4-hBP, 4-Cl-4hBP, and 2-Cl-HQ, with molecular structures shown in Table S5) were selected to investigate the effect of hydroxyl or chlorine addition on the $\Phi_{3 \mathrm{DOM}^{*}}$ of DOM. BP and HQ contain ketone and phenol functional groups and these chemicals were selected since ketones and phenols are the main chromophores of DOM (McNeill and Canonica, 2016). And 4-hBP, 4-Cl-4hBP, and 2-Cl-HQ are corresponding hydroxylated and/or chlorinated products of $\mathrm{BP}$ and $\mathrm{HQ}$.

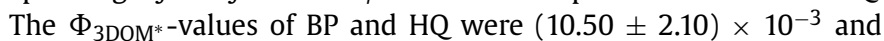
$(0.174 \pm 0.010) \times 10^{-3}$, respectively, while the values of $\Phi_{3 \mathrm{DOM}^{*}}$ of 4 -hBP, $4-\mathrm{Cl}-4 \mathrm{hBP}$ and $2-\mathrm{Cl}-\mathrm{HQ}$ were $(0.036 \pm 0.002) \times 10^{-3}$, $(0.033 \pm 0.002) \times 10^{-3}$ and $(0.145 \pm 0.015) \times 10^{-3}$, respectively (Table 1$)$. The $\Phi_{3 \mathrm{DOM}^{*}}$ of hydroxylation or/and chlorination products are lower than those of BP and HQ. Thus, it can be concluded that the $\Phi_{3 \mathrm{DOM}^{*}}$ of DOM is significantly decreased after hydroxyl or chlorine addition.

As the chlorine dosage was increased to 75-200 $\mu \mathrm{M}$, the $\Phi_{3 D_{0 M}} *$ values of SRFA-UV/Cl gradually increased, and were higher than that of SRFA. This is attributed to the single-electron transfer reactions induced by $\mathrm{RCS}$ or $\cdot \mathrm{OH}$ at high concentrations (Fig. S3). The phenolic structures undergo electron transfer reactions, which leads to the formation of the semiquinone/quinone radical, which then converts to the corresponding semiquinones/quinones in the presence of molecular oxygen (Rodríguez and von Gunten, 2020; Zhang et al., 2016). The hydroxyl groups could also be added to the alkyl functionality of DOM, and then undergo further oxidation reactions or dehydration of two adjacent hydroxyl groups, which leads to the formation of ketones with conjugated $\pi$ bonds during UV/chlorine treatment (Duan et al., 2018). Both quinones and 

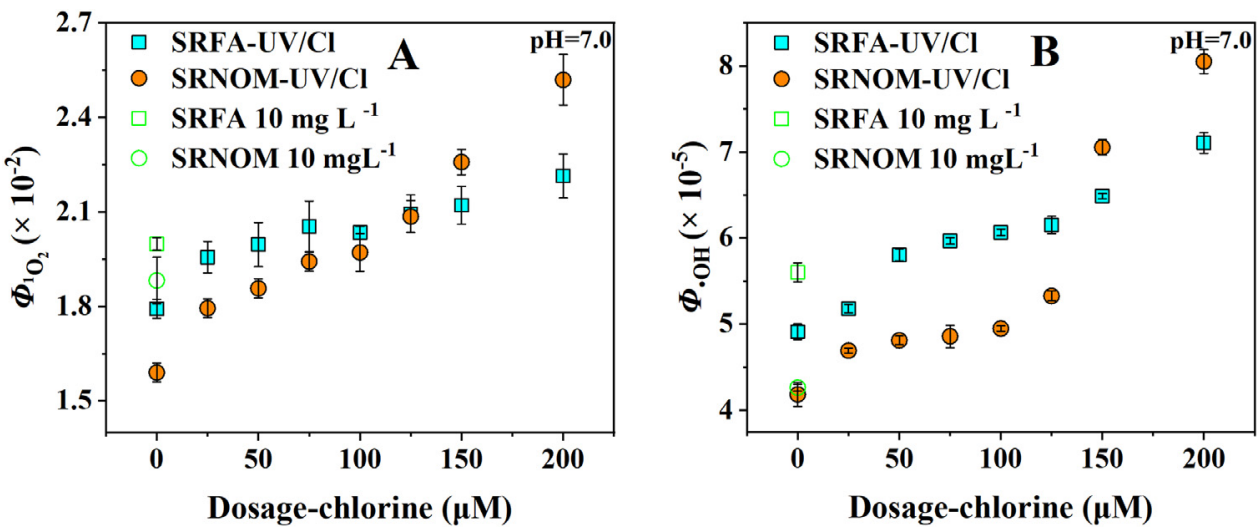

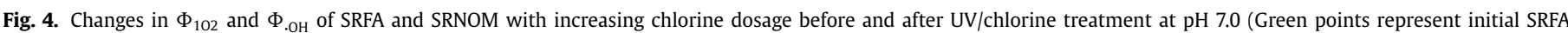

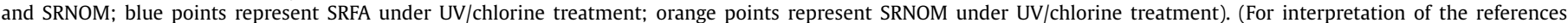
to colour in this figure legend, the reader is referred to the web version of this article.)

ketones could generate high-energy excited triplets with average energies of approximately $231 \mathrm{~kJ} \mathrm{~mol}^{-1}$ and $285 \mathrm{~kJ} \mathrm{~mol}^{-1}$, respectively (Zhou et al., 2019a).

The $p-\mathrm{BQ}$ (molecular structure is shown in Table S5), a quinone product of HQ oxidation was used to assess discuss the effect of a quinone functionality on $\Phi_{3 \mathrm{DOM}^{*}}$. The results showed that the $\Phi_{3 \mathrm{DOM}^{*}}$ of HQ $\left((0.174 \pm 0.010) \times 10^{-3}\right)$ is lower than that of $p$ $\mathrm{BQ}\left((0.221 \pm 0.025) \times 10^{-3}\right)$ (Table 1$)$. Furthermore, the values of $\Phi_{3 \mathrm{DOM}^{*}}$ of BP determined here are in general quite high when compared with other substances. As a consequence, the formation of quinone and ketone functional groups is the causes for the increase of $\Phi_{3 \mathrm{DOM}^{*}}$ during $\mathrm{UV} /$ chlorine treatment with high chlorine dosage.

The trend in the variation of $\Phi_{3 \mathrm{DOM}^{*}}$ for SRNOM upon increase of the chlorine dosage under UV/chlorine treatment is similar to the trend for SRFA (Fig. 3). However, upon increasing the chlorine dosage, SRNOM-UV/Cl has a higher value of $\Phi_{3 \mathrm{DOM}^{*}}$ than SRFA-UV/Cl due to the structural differences of SRNOM and SRFA. The steady-state concentration of ${ }^{3} \mathrm{DOM}^{*}\left(\left[{ }^{3} \mathrm{DOM}^{*}\right]_{\mathrm{SS}}\right)$ produced by SRFA-UV/Cl and SRNOM-UV/Cl decreased with the increase of chlorine dosage during $\mathrm{UV} /$ chlorine treatment (Fig. S4), This is contrary to the variation trends of the variation of $\Phi_{3 \mathrm{DOM}^{*}}$ for SRFA-UV/Cl and SRNOM-UV/Cl. This finding is attributed to the absorbance changes of SRFA and SRNOM at $\lambda>290 \mathrm{~nm}$ during UV/chlorine treatment. With the chlorine dosage increasing from 0 to $200 \mu \mathrm{M}$, SUVA $_{\text {avg }}$ of SRFA and SRNOM decreased from 5.12 to $1.42 \mathrm{~L} \mathrm{mgC}^{-1}$ $\mathrm{m}^{-1}$ and from 3.46 to $0.72 \mathrm{~L} \mathrm{mgC}^{-1} \mathrm{~m}^{-1}$, respectively (Table S6). The SUVA avg reduction of more than 3 times compared to the initial DOM led to the reduction of $\left[{ }^{3} \mathrm{DOM}^{*}\right]_{S S}$ in SRFA-UV/Cl and SRNOM-UV/Cl solutions.

\subsection{Effect of UV/chlorine treatment on ${ }^{1} \mathrm{O}_{2}$ and $\cdot \mathrm{OH}$ generation from SRFA and SRNOM}

The quantum yields of ${ }^{1} \mathrm{O}_{2}\left(\Phi_{102}\right)$ produced by SRFA and SRNOM decreased at first and then increased with the increase of chlorine dosage under UV/chlorine treatment (Fig. 4A). These variation trends are coincident with that of the $\Phi_{3 \mathrm{DOM}^{*}}$ for the two types of DOM. Meanwhile, with the increase of chlorine dosage, the $\Phi_{3 \text { DOM }^{*}}$ and the $\Phi_{102}$ of SRFA-UV/Cl and SRNOM-UV/Cl showed a positively linear correlation $\left(R^{2}>0.975\right)$ (Fig. S5A and $B)$. This is attributed to generation of ${ }^{1} \mathrm{O}_{2}$ through energy transfer reactions between dissolved oxygen and ${ }^{3} \mathrm{DOM}^{*}$, i.e., ${ }^{3} \mathrm{DOM}^{*}$ is the precursor of ${ }^{1} \mathrm{O}_{2}$ (McNeill and Canonica, 2016). In a previous study, the $\Phi_{102}$ from different sources of DOM was also related to the $\Phi_{\text {3DOM* }}$ (McKay et al., 2017). Moreover, in case of SRNOM-UV/Cl
(0.206) was lower than the slope in case of SRFA-UV/Cl $(0.233)$ (Fig. S5A and B). The slope is reported to be positively correlated to the transformation ability from ${ }^{3} \mathrm{DOM}^{*}$ to ${ }^{1} \mathrm{O}_{2}$ (McKay et al., 2017). Similarly, the positively linear correlations between $\left[{ }^{1} \mathrm{O}_{2}\right]_{\mathrm{SS}}$ and $\left[{ }^{3} \mathrm{DOM}^{*}\right]_{\mathrm{SS}}$ produced by SRFA-UV/Cl and SRNOM-UV/Cl were observed and the slope for SRFA-UV/Cl was higher compared with the slope of SRNOM-UV/Cl (Fig. S6A and B). Thus, the excited triplet states of SRNOM-UV/Cl were more difficult to transform to ${ }^{1} \mathrm{O}_{2}$ compared with the excited triple states of SRFA-UV/Cl after $\mathrm{UV} /$ chlorine treatment.

The $\Phi_{102}$-values for the selected low molecule DOM analogs were calculated and the results showed that the $\Phi_{102}$ for BP $\left((8.48 \pm 0.09) \times 10^{-2}\right)$ containing a ketone functionality and for p-BQ $\left((2.92 \pm 0.01) \times 10^{-2}\right)$ with a quinone functional group were much higher than the value of $\Phi_{102}$ for the other analogs, which is in accordance with the results observed in previous literature (Leresche et al., 2019; McNeill and Canonica, 2016). Thus, the formation of quinone and ketone functional groups during the $\mathrm{UV} /$ chlorine treatment are the reason for the increase of the $\Phi_{102}$ from SRFA and SRNOM.

For $\cdot \mathrm{OH}$, an increase was observed of the quantum yields of $\cdot \mathrm{OH}$ $\left(\Phi_{. \mathrm{OH}}\right.$ ) for SRFA-UV/Cl and SRNOM-UV/Cl (Fig. 4B) and a decrease in $[\cdot \mathrm{OH}]_{\mathrm{SS}}$ of these two DOM with increasing chlorine dosage during UV/chlorine treatment (Fig. S4). Furthermore, the obtained results showed that the $\Phi_{\text {.OH }}$ and $[\cdot \mathrm{OH}]_{S S}$ were positively linear correlated with $\Phi_{3 \mathrm{DOM}^{*}}$ and $\left[{ }^{3} \mathrm{DOM} *\right]_{S S}$, respectively (Fig. S5C and D; Fig. S6C and D). However, values of the correlation coefficients $\left(R^{2}\right)$ of $\Phi_{3 \mathrm{DOM}^{*}}$ with $\Phi_{\text {.OH }}$ for SRFA-UV/Cl and SRNOM-UV/Cl were 0.893 and 0.760 , respectively, both of which were lower than the values of $\Phi_{3 \text { DOM }^{*}}$ with $\Phi_{102}(0.985$ for SRFA-UV/Cl and 0.975 for SRNOM-UV/Cl).

Previous studies had reported that ${ }^{3} \mathrm{DOM}^{*}$ is not a direct precursor of $\cdot \mathrm{OH}$, but ${ }^{3} \mathrm{DOM}^{*}$ could be used as a precursor for lowenergy hydroxylators (McKay et al., 2017). The generation pathways of $\cdot \mathrm{OH}$ from DOM are complicated under light irradiation. The superoxide radical anion $\left(\mathrm{O}_{2} \cdot-\right)$ is firstly generated during electron transfer reactions between ${ }^{3} \mathrm{DOM}^{*}$ and dissolved oxygen, and subsequently undergoes dismutation to form hydrogen peroxide $\left(\mathrm{H}_{2} \mathrm{O}_{2}\right)$ and eventually $\cdot \mathrm{OH}$ (Vione et al., 2014)

Furthermore,. $\mathrm{OH}$ could also be produced by the reaction of ${ }^{3} \mathrm{DOM}^{*}$ with the hydroxide ion $\left(\mathrm{OH}^{-}\right)$in water, which only occur for DOM containing a small amount of structures such as quinones, as the excited quinones have a higher reduction potential $\left(E_{0}\right.$ (quinones) $\left.>2.19 \mathrm{~V}>E_{0}\left(\mathrm{OH}^{-}\right)=1.77 \mathrm{~V}\right)($ McNeill and Canonica, 2016). As can be seen from Table 1 , the $\Phi_{. \mathrm{oH}}$ of $p$ BQ $\left((9.56 \pm 0.32) \times 10^{-5}\right)$ was higher than the $\Phi_{. \mathrm{OH}}$ of HQ 

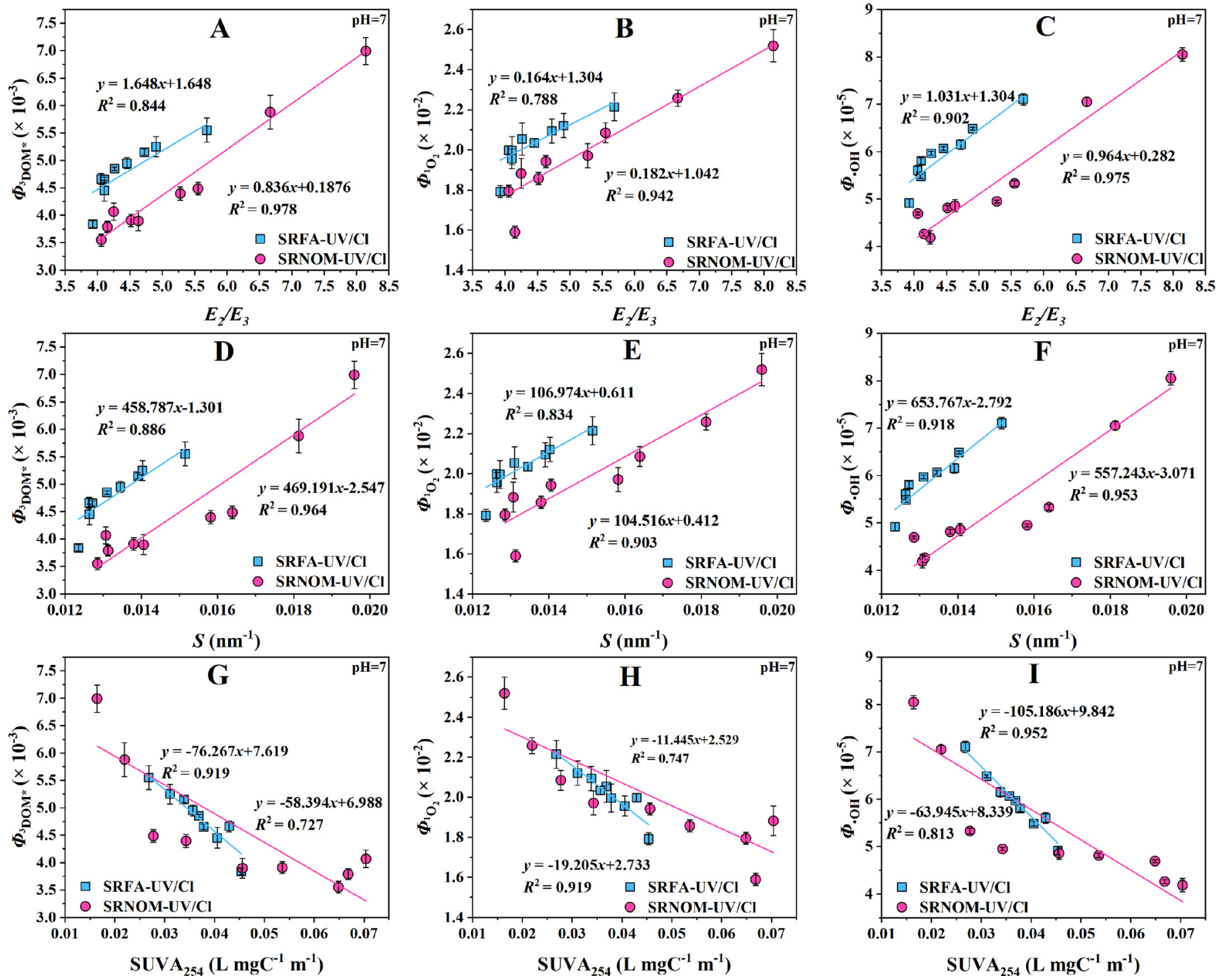

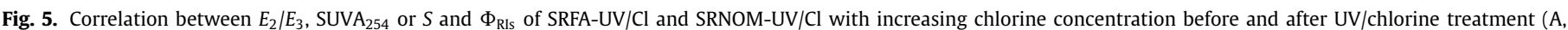

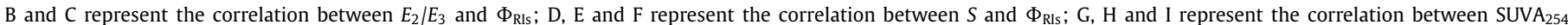
and $\Phi_{\mathrm{RIS}}$ ).

$\left((3.17 \pm 0.12) \times 10^{-5}\right)$. Thus, the generation of quinone groups in the two DOM could lead to the increase of $\Phi_{. \mathrm{OH}}$.

\subsection{Correlation between photophysical properties and photochemical properties}

As shown in Fig. 5, in the UV/chlorine system with different chlorine dosages, the $\Phi_{\mathrm{RIs}}$ of SRFA-UV/Cl and SRNOM-UV/Cl had a good linear correlation with $E_{2} / E_{3}, S$, and $S_{U V A}{ }_{254}$, among which $E_{2} / E_{3}$ and $S$ were positively linear correlated with the $\Phi_{\mathrm{RIs}}(0.788$ $<R^{2}<0.918$ ), whereas $\mathrm{SUVA}_{254}$ was negatively linear correlated with the $\Phi_{\mathrm{RIs}}\left(0.727<R^{2}<0.952\right)$. These findings implied that the DOM with lower molecular weight, aromaticity and electrondonating capacity has the higher $\Phi_{\text {RIs }}$. Previous studies also suggested that the photochemical properties of DOM were related to its molecular weight, aromaticity, and electron-donating capacity (Dalrymple et al., 2010; McKay et al., 2017). This is attributed to the intramolecular interactions of DOM (e.g., energy transfer or electron transfer) (Ma et al., 2010; Sharpless and Blough, 2014), as the closely-connected electron-donating structures and electronaccepting structures of DOM have higher ability to absorb light and produce photochemical reactive species (McKay et al., 2016). Thus, the UV/chlorine treatment induced changes of molecular weight, aromaticity or electron-donating capacity of DOM can influence the generation of the photo-chemically reactive species from DOM.

Overall, the trends in the variation of the photophysical and photochemical properties of SRFA and SRNOM were similar in the UV/chlorine treatment with different chlorine dosages. However, the range of variation of all the parameters, including $E_{2} / E_{3}$, $S$, SUVA 254 , and $\Phi_{\mathrm{RIs}}$ of SRNOM was wider than in case of SRFA (Figs. 2; 3; 4). SRFA is the fulvic acid component isolated from Suwanee River, while SRNOM is consisted of fulvic acid, humic acid and other organic matters isolated from Suwanee River (Green et al., 2015).Thus, these results indicated that RCS and $\cdot \mathrm{OH}$ produced in the $\mathrm{UV} /$ chlorine system could not only affect the photophysical and photochemical properties of the fulvic acid component but also other components of DOM (e.g., humic acid). 

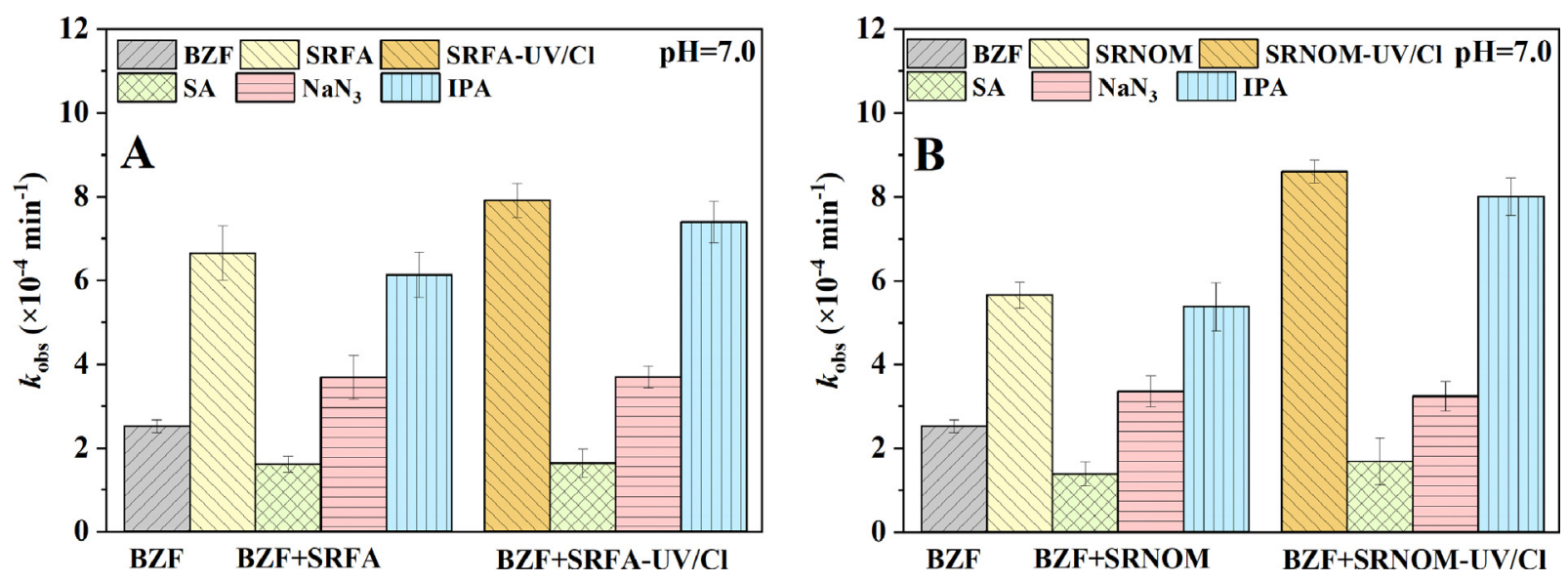

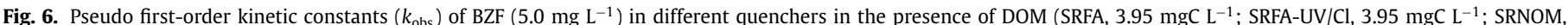
$4.10 \mathrm{mgC} \mathrm{L}^{-1}$; SRNOM-UV/Cl, $4.10 \mathrm{mgC} \mathrm{L}^{-1}$; SA, sorbic acid, $2 \mathrm{mM}$; $\mathrm{NaN}_{3}, 2 \mathrm{mM}$; IPA, isopropanol, $20 \mathrm{mM}$ ).

\subsection{Effect of SRFA-UV/Cl and SRNOM-UV/Cl on photodegradation of BZF under simulated sunlight irradiation}

The DOM released from WWTPs or from wastewater treated by UV/chlorine can alter the photoreactivity of natural DOM in the receiving waters, and further influence the photodegradation of organic pollutants in natural water (Zhang et al., 2014). Thus, the effect of SRFA-UV/Cl and SRNOM-UV/Cl on the photodegradation of BZF under simulated sunlight irradiation was investigated. The photodegradation rate constant $\left(k_{\mathrm{obs}}\right)$ of BZF in phosphate buffer solution (PBS, $\mathrm{pH}=7.0$ ) was determined to be $(2.51 \pm 0.15) \times 10^{-4}$ $\mathrm{min}^{-1}$ (Fig. 6). The extremely low molar absorptivity of BZF at wavelengths $>290 \mathrm{~nm}$ was the reason for its persistence to photodegradation (Fig. S7). However, faster photodegradation was observed for BZF in solutions containing SRFA, SRNOM, SRFA-UV/Cl and SRNOM-UV/Cl, and the photodegradation of BZF was more effectively promoted in the presence of SRFA-UV/Cl and SRNOM$\mathrm{UV} / \mathrm{Cl}$ (Fig. 6). It is indicated that DOM-induced indirect photodegradation is an important degradation pathway of BZF in surface water, and the DOM after UV/chlorine treatment plays more important roles in the photochemical degradation of BZF, which may affect the environmental persistence of BZF in the receiving water.

The role of reactive ${ }^{3} \mathrm{DOM}^{*},{ }^{1} \mathrm{O}_{2}$, and $\cdot \mathrm{OH}$ in the photodegradation of BZF sensitized by SRFA, SRNOM, SRFA-UV/Cl and SRNOM$\mathrm{UV} / \mathrm{Cl}$ was investigated, and the results are shown in Fig. 6. Addition of SA obviously inhibited the photodegradation of BZF, implying that the excited triplet states of these DOM play important roles in the photodegradation of BZF. $\mathrm{NaN}_{3}$ and IPA significantly inhibited the photodegradation of BZF, while the effect of IPA is much weaker compared with that of $\mathrm{SA}$ and $\mathrm{NaN}_{3}$. Consequently, these DOM predominantly promote the photodegradation of BZF through the generation of their excited triplet state, followed by ${ }^{1} \mathrm{O}_{2}$, whereas $\cdot \mathrm{OH}$ plays a minor role in the photodegradation of BZF.

\section{Conclusion}

This study evaluated the effect of a practical wastewater treatment process, UV/chlorine treatment, on the photophysical and photochemistry properties of DOM. The reactive species generated in the UV/chlorine system were found to be able to significantly decrease the aromaticity, molecular weight, and electron-donating capacity of SRFA and SRNOM. This leads to the inhibitory effects on the absorbance abilities of the two DOM. At low chlorine dosages, the $\Phi_{\mathrm{RIs}}$ of the two DOM was decreased due to the hydroxylation and/or chlorination reactions. On the contrary, the $\Phi_{\mathrm{RIs}}$ was increased at high chlorine dosages due to the formation of aromatic ketone or quinone functionalities. In addition, DOM with lower molecular weight, aromaticity and electron-donating capacity have the highest values of $\Phi_{\text {RIs }}$. The DOM treated by UV/chlorine more effectively promoted the photodegradation of BZF and the promotional effect is mainly attributed to the contribution of the excited triplet states, followed by reaction with ${ }^{1} \mathrm{O}_{2}$ and $\cdot \mathrm{OH}$. The results of this study indicated that the photophysical and photochemical properties of DOM are changed during UV/chlorine treatment, which further affects the role of DOM in the photodegradation of micropollutants and may further alter the properties of natural DOM.

\section{Declaration of Competing Interest}

The authors declare that they have no known competing financial interests or personal relationships that could have appeared to influence the work reported in this paper.

\section{Acknowledgements}

This study was supported by the National Natural Science Foundation of China (21707017, 41877364, 21976027), the Fundamental Research Funds for the Central Universities (2412019FZ019), and the Jilin Province Science and Technology Development Projects (20190303068SF, 20200301012RQ).

\section{Supplementary materials}

Supplementary material associated with this article can be found, in the online version, at doi:10.1016/j.watres.2021.116857.

\section{References}

Apell, J.N., Pflug, N.C., McNeill, K., 2019. Photodegradation of fludioxonil and other pyrroles: the importance of indirect photodegradation for understanding environmental fate and photoproduct formation. Environ. Sci. Technol. 53 (19), 11240-11250.

Bodhipaksha, L.C., Sharpless, C.M., Chin, Y., Sander, M., Langston, W.K., MacKay, A.A., 2015. Triplet photochemistry of effluent and natural organic matter in whole water and isolates from effluent-receiving rivers. Environ. Sci. Technol. 49 (6), 3453-3463.

China, HJ 586-2010 (Dec 1, 2010).

Dalrymple, R.M., Carfagno, A.K., Sharpless, C.M., 2010. Correlations between dissolved organic matter optical properties and quantum yields of singlet oxygen and hydrogen peroxide. Environ. Sci. Technol. 44 (15), 5824-5829.

Dong, M.M., Rosario-Ortiz, F.L., 2012. Photochemical formation of hydroxyl radical from effluent organic matter. Environ. Sci. Technol. 46 (7), 3788-3794. 
Duan, X., Sanan, T., Cruz, A., He, X., Kong, M., Dionysiou, D.D., 2018. Susceptibility of the algal toxin microcystin-LR to UV/chlorine process: comparison with chlorination. Environ. Sci. Technol. 52 (15), 8252-8262.

Fang, J., Fu, Y., Shang, C., 2014. The roles of reactive species in micropollutant degradation in the UV/free chlorine system. Environ. Sci. Technol. 48 (3), 1859-1868.

Gao, Z., Lin, Y., Xu, B., Xia, Y., Hu, C., Zhang, T., Cao, T., Chu, W., Gao, N., 2019. Effect of UV wavelength on humic acid degradation and disinfection by-product formation during the UV/chlorine process. Water Res 154, 199-209.

Ge, L., Zhang, P., Halsall, C., Li, Y., Chen, C., Li, J., Sun, H., Yao, Z., 2019. The importance of reactive oxygen species on the aqueous phototransformation of sulfonamide antibiotics: kinetics, pathways, and comparisons with direct photolysis. Water Res 149, 243-250.

Gilbert, B.C., Stell, J.K., Peet, W.J., Radford, K.J., 1988. Generation and reactions of the chlorine atom in aqueous solution. J. Chem. Soc. 84 (10), 3319-3330.

Green, N.W., McInnis, D., Hertkorn, N., Maurice, P.A., Perdue, E.M., 2015. Suwannee river natural organic matter: isolation of the $2 \mathrm{R} 101 \mathrm{~N}$ reference sample by reverse osmosis. Environ. Eng. Sci. 32 (1), 38-44.

Guo, K., Wu, Z., Shang, C., Yao, B., Hou, S., Yang, X., Song, W., Fang, J., 2017. Radical chemistry and structural relationships of PPCP degradation by UV/chlorine treatment in simulated drinking water. Environ. Sci. Technol. 51 (18), 10431-10439.

Helms, J.R., Stubbins, A., Ritchie, J.D., Minor, E.C., Kieber, D.J., Mopper, K., 2008. Absorption spectral slopes and slope ratios as indicators of molecular weight, source, and photobleaching of chromophoric dissolved organic matter. Limnol. Oceanogr. 53, 955-969.

Ianni, J.C., 2019. Kintecus, Version 6.8. http://kintecus.com/.

Janssen, E.M.L., Erickson, P.R., McNeill, K., 2014. Dual roles of dissolved organic matter as sensitizer and quencher in the photooxidation of tryptophan. Environ. Sci. Technol. 48 (9), 4916-4924.

Korshin, G.V., Benjamin, M.M., Chang, H., Gallard, H., 2007. Examination of NOM chlorination reactions by conventional and stop-flow differential absorbance spectroscopy. Environ. Sci. Technol. 41 (8), 2776-2781.

Laszakovits, J.R., Somogyi, A., MacKay, A.A., 2020. Chemical alterations of dissolved organic matter by permanganate oxidation. Environ. Sci. Technol. 54 (6), 3256-3266.

Lee, E., Glover, C.M., Rosario-Ortiz, F.L., 2013. Photochemical formation of hydroxyl radical from effluent organic matter: role of composition. Environ. Sci. Technol. 47 (21), 12073-12080.

Lei, Y., Cheng, S., Luo, N., Yang, X., An, T., 2019. Rate constants and mechanisms of the reactions of $\mathrm{Cl}$. and $\mathrm{Cl}_{2} \cdot-$ with trace organic contaminants. Environ. Sci. Technol. 53 (19), 11170-11182.

Leresche, F., McKay, G., Kurtz, T., von Gunten, U., Canonica, S., Rosario-Ortiz, F.L., 2019. Effects of ozone on the photochemical and photophysical properties of dissolved organic matter. Environ. Sci. Technol. 53 (10), 5622-5632.

Ma, J., del Vecchio, R., Golanoski, K.S., Boyle, E.S., Blough, N.V., 2010. Optical properties of humic substances and CDOM: effects of borohydride reduction. Environ. Sci. Technol. 44 (14), 5395-5402.

McKay, G., Couch, K.D., Mezyk, S.P., Rosario-Ortiz, F.L., 2016. Investigation of the coupled effects of molecular weight and charge-transfer interactions on the optical and photochemical properties of dissolved organic matter. Environ. Sci. Technol. 50 (15), 8093-8102.

McKay, G., Huang, W., Romera-Castillo, C., Crouch, J.E., Rosario-Ortiz, F.L., Jaffé, R., 2017. Predicting reactive intermediate quantum yields from dissolved organic matter photolysis using optical properties and antioxidant capacity. Environ. Sci. Technol. 51 (10), 5404-5413.

McKay, G., Korak, J.A., Erickson, P.R., Latch, D.E., McNeill, K., Rosario-Ortiz, F.L., 2018. The case against charge transfer interactions in dissolved organic matter photophysics. Environ. Sci. Technol. 52 (2), 406-414.

McNeill, K., Canonica, S., 2016. Triplet state dissolved organic matter in aquatic photochemistry: reaction mechanisms, substrate scope, and photophysical properties. Environ. Sci.: Process. Impacts 18 (11), 1381-1399.

Mostafa, S., Rosario-Ortiz, F.L., 2013. Singlet oxygen formation from wastewater organic matter. Environ. Sci. Technol. 47 (15), 8179-8186.

Rodríguez, E.M., von Gunten, U., 2020. Generation of hydroxyl radical during chlorination of hydroxyphenols and natural organic matter extracts. Water Res 117, 115691.

Sharpless, C.M., Aeschbacher, M., Page, S.E., Wenk, J., Sander, M., McNeill, K., 2014. Photooxidation-induced changes in optical, electrochemical, and photochemical properties of humic substances. Environ. Sci. Technol. 48 (5), 26882696.
Sharpless, C.M., Blough, N.V., 2014. The importance of chargetransfer interactions in determining chromophoric dissolved organic matter (CDOM) optical and photochemical properties. Environ. Sci.: Process. Impacts 16 (4), 654-671.

Twardowski, M.S., Boss, E., Sullivan, J.M., Donaghay, P.L., 2004. Modeling the spectral shape of absorption by chromophoric dissolved organic matter. Mar. Chem. 89 $(1-4), 69-88$

Varanasi, L., Coscarelli, E., Khaksari, M., Mazzoleni, L.R., Minakata, D., 2018. Transformations of dissolved organic matter induced by UV photolysis, hydroxyl radicals, chlorine radicals, and sulfate radicals in aqueous-phase UV-based advanced oxidation processes. Water Res. 135, 22-30.

Vione, D., Minella, M., Maurino, V., Minero, C., 2014. Indirect photochemistry in sunlit surface waters: photoinduced production of reactive transient species. Chem. Eur. J. 20 (34), 10590-10606.

Walpen, N., Schroth, M.H., Sander, M., 2016. Quantification of phenolic antioxidant moieties in dissolved organic matter by flow-injection analysis with electrochemical detection. Environ. Sci. Technol. 50 (12), 6423-6432.

Wang, H., Zhou, H., Ma, J., Nie, J., Yan, S., Song, W., 2020. Triplet photochemistry of dissolved black carbon and its effects on the photochemical formation of reactive oxygen species. Environ. Sci. Technol. 54 (8), 4903-4911.

Wang, J., Chen, J., Qiao, X., Wang, Y., Cai, X., Zhou, C., Zhang, Y., Ding, G., 2018. DOM from mariculture ponds exhibits higher reactivity on photodegradation of sulfonamide antibiotics than from offshore seawaters. Water Res. 144, 365-372.

Wang, J., Chen, J., Qiao, X., Zhang, Y., Uddin, M., Guo, Z., 2019. Disparate effects of DOM extracted from coastal seawaters and freshwaters on photodegradation of 2,4-dihydroxybenzophenone. Water Res. 151, 280-287.

Weishaar, J.L., Aiken, G.R., Bergamaschi, B.A., Fram, M.S., Fujii, R., Mopper, K., 2003. Evaluation of specific ultraviolet absorbance as an indicator of the chemical composition and reactivity of dissolved organic carbon. Environ. Sci. Technol. 37 (20), 4702-4708.

Xiang, Y., Fang, J., Shang, C., 2016. Kinetics and pathways of ibuprofen degradation by the UV/chlorine advanced oxidation process. Water Res. 90, 301-308.

Yan, M., Korshin, G.V., Chang, H., 2014. Examination of disinfection by-product (DBP) formation in source waters: a study using log-transformed differential spectra. Water Res. 50, 179-188.

Zark, M., Dittmar, T., 2018. Universal molecular structures in natural dissolved organic matter. Nat. Commun. 9 (1), 3178.

Zhang, D., Yan, S., Song, W., 2014. Photochemically induced formation of reactive oxygen species (ROS) from effluent organic matter. Environ. Sci. Technol. 48 (21), 12645-12653.

Zhang, K., Parker, K.M., 2018. Halogen radical oxidants in natural and engineered aquatic systems. Environ. Sci. Technol. 52 (17), 9579-9594.

Zhang, T., Cheng, L., Ma, L., Meng, F., Arnold, R.G., Saez, A.E., 2016. Modeling the oxidation of phenolic compounds by hydrogen peroxide photolysis. Chemosphere 161, 349-357.

Zhang, Y., Wang, J., Chen, J., Zhou, C., Xie, Q., 2018a. Phototransformation of 2,3-dibromopropyl-2,4,6-tribromophenyl ether (DPTE) in natural waters: important roles of dissolved organic matter and chloride ion. Environ. Sci. Technol. 52 (18), 10490-10499.

Zhang, Y., Zhou, Y., Qu, J., Chen, J., Zhao, J., Lu, Y., Li, C., Xie, Q., Peijnenburg, W.J.G.M., 2018b. Unveiling the important roles of coexisting contaminants on photochemical transformations of pharmaceuticals: fibrate drugs as a case study. J. Hazard Mater. 358, 216-221.

Zhao, J., Zhou, Y., Li, C., Xie, Q., Chen, J., Chen, G., Peijnenburg, W.J.G.M., Zhang, Y., Qu, J., 2020. Development of a quantitative structure-activity relationship model for mechanistic interpretation and quantum yield prediction of singlet oxygen generation from dissolved organic matter. Sci. Total Environ. 712, 136450.

Zhou, C., Chen, J., Xie, H., Zhang, Y., Li, Y., Wang, Y., Xie, Q., Zhang, S., 2018. Modeling photodegradation kinetics of organic micropollutants in water bodies: a case of the yellow river estuary. J. Hazard. Mater. 349, 60-67.

Zhou, H., Yan, S., Lian, L., Song, W., 2019a. Triplet-state photochemistry of dissolved organic matter: triplet-state energy distribution and surface electric charge conditions. Environ. Sci. Technol. 53 (5), 2482-2490.

Zhou, S., Zhang, W., Sun, J., Zhu, S., Li, K., Meng, X., Luo, J., Shi, Z., Zhou, D., Crittenden, J.C., 2019b. Oxidation mechanisms of the UV/free chlorine process: kinetic modeling and quantitative structure activity relationships. Environ. Sci. Technol. 53 (8), 4335-4345.

Zhou, Y., Zhao, J., Zhang, Y., Qu, J., Li, C., Qin, W., Zhao, Y., Chen, J., Peijnenburg, W.J.G.M., 2019c. Trace amounts of fenofibrate acid sensitize the photodegradation of bezafibrate in effluents: mechanisms, degradation pathways, and toxicity evaluation. Chemosphere 235, 900-907. 